\title{
Erratum to: Lactosaminated mesoporous silica nanoparticles for asialoglycoprotein receptor targeted anticancer drug delivery
}

Guilan Quan' ${ }^{1}$ Xin Pan ${ }^{1}$, Zhouhua Wang ${ }^{1}$, Qiaoli Wu' ${ }^{1}$ Ge Li², Linghui Dian³ ${ }^{3}$ Bao Chen ${ }^{\text {** }}$ and Chuanbin $\mathrm{Wu}^{1 *}$

\section{Erratum to: J Nanobiotechnol DOI 10.1186/s12951-015-0068-6}

Panel A, B, and C from Figure 7 (Fig. 1 here) of this work [1] was generated using HepG2, SMMC7721, and NIH 3T3 cells, respectively. After publication of this work, we noted that they were inadvertently labelled as $\mathrm{NIH}$ 3T3, HepG2 and SMMC7721 cells. The figure caption of Figure 7 has now been corrected in this erratum.

\section{Author details}

${ }^{1}$ School of Pharmaceutical Sciences, Sun Yat-Sen University, Guangzhou 510006, People's Republic of China. ${ }^{2}$ Guangzhou Neworld Pharmaceutical Ltd. Co., Guangzhou 510006, People's Republic of China. ${ }^{3}$ School of Pharmaceutical Sciences, Guangdong Medical College, Dongguan 523808, People's Republic of China.
The online version of the original article can be found under doi:10.1186/s12951-015-0068-6.

Received: 11 June 2015 Accepted: 11 June 2015

Published online: 30 November 2015

\section{Reference}

1. Quan GL, Pan X, Wang ZH, Wu QL, Li G, Dian LH et al (2015) Lactosaminated mesoporous silica nanoparticles for asialoglycoprotein receptor targeted anticancer drug delivery. J Nanobiotech 13:7
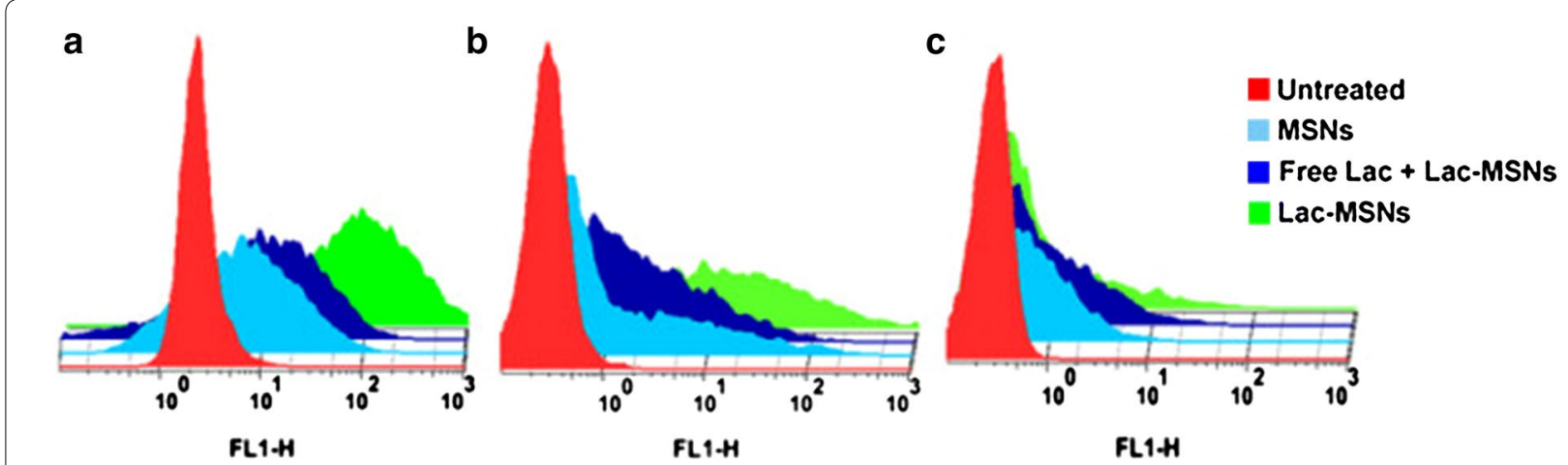

Figure 1 Flow cytometry study. ASGPR-positive cells HepG2 (A) and SMMC7721 (B), and ASGPR-negative cells NIH 3T3 (C) incubated with blank medium (control), Lac-MSNs, MSNs, and excess free lactose with Lac-MSNs for $4 \mathrm{~h}$ at $37^{\circ} \mathrm{C}$. Data represent mean \pm SD $(n=3)$.

\footnotetext{
*Correspondence: Isscb@mail.sysu.edu.cn; chuanbin_wu@126.com

${ }^{1}$ School of Pharmaceutical Sciences, Sun Yat-Sen University,

Guangzhou 510006, People's Republic of China

Full list of author information is available at the end of the article
} 